\title{
Designing Badges for a Civic Media Platform: Reputation and Named levels
}

\author{
Stefano De Paoli \\ $<$ ahref Foundation \\ Vicolo Dallapiccola, Trento (Italy) \\ Stefano@ahref.eu
}

\author{
Nicolò De Uffici \\ $<$ ahref Foundation \\ Vicolo Dallapiccola, Trento (Italy) \\ nico.deuffici@gmail.com
}

\author{
Vincenzo D'Andrea \\ University of Trento \\ Via Sommarive, Trento (Italy) \\ vincenzo.dandrea@unitn.it
}

\begin{abstract}
Badges are gaining momentum on the social web but known $\mathrm{HCl}$ design experiences are very few. In this paper we present a design experience related to badges and named levels for representing reputation within the context of a Civic Media Platform called timu. We describe our design methodology and the exercise we have devised for designing named levels together with users. We then describe our design vision which unites contextual details about timu together with the rhetoric of progression provided by the language proficiency system. In the conclusion we generalise our design results.
\end{abstract}

Badges, named levels, interaction design, civic media, reputation, reputation systems.

\section{INTRODUCTION}

The advent of the networked digital society has brought an increased level of citizen engagement in civic life (Gillmor, 2004) through the means of Civic Media (web) Platforms (CMPs). Civic Media can be defined as any "medium" that fosters civic engagement and direct participation of people to civic life (Jenkins, 2007). The internet and social media allow a strong civic engagement of citizens that can take advantage of a many-to-many communication.

For CMP participants being able to recognise, formalise and display skills, achievements or reputation acquired with their participation is of crucial importance. This in turn could help participants to unlock further civic opportunities (including work opportunities), formalizing what they have informally learned and facilitating interactions among themselves. Badges, we believe, can greatly help participants in formalizing, assessing and displaying what has been achieved in a CMP. A badge can be defined as a visual representation of an accomplishment, skill or reputation gained in the context of a specific community or institutional setting. A legacy of badges can be found in the military where they represent rank and authority or in the scout movement where they represent pupils' achievements (Halavais, 2011).

Although badges are in widespread use in web platforms relatively little research exists providing lively and detailed badge design experiences. In this paper we describe our experience in the design of a badge system for a CMP platform called timu (http://www.timu.it/) developed by the <ahref Foundation (http://www.ahref.eu/en) in Italy and whose goal is to enable citizens to collectively contribute to a bottom-up information ecosystem (De Biase, 2011). We propose the design of a badge system whose goal is to be a visual and efficient representation of the reputation of participants in timu. Specifically, the timu reputation can primarily be seen as a measure of how a user has contributed to the goals of the platform and to the development of the community. The badges will therefore be awarded by the timu platform after tracking user participation and contribution to the platform goals.

In the remainder of the paper we will: analyze the concept of badges in the Human Computer Interaction $(\mathrm{HCl})$ literature; describe the reputation system of timu; introduce the requirements for the timu badge system; describe our design methodology; present the result of our design and the first sketch of the badge system for timu.

\section{BADGES ON THE WEB AND IN HCI}

Designing effective and usable badge systems for the web is an important task for $\mathrm{HCl}$ research. Badges are increasingly becoming an important component of social media user interfaces, whose goal is to facilitate interactions among users and make the quality of the user profile explicit. An increasing number of mainstream social networks (e.g. Foursquare), online multiplayer games/platforms (e.g. World of Warcraft, Xbox 
Live) and other, more civic or learning oriented, web platforms (e.g. Newstrust in citizen journalism http://newstrust.net/, stackoverflow in computer programming Q/A http://stackoverflow.com/) - just to mention a few known cases - use badges for representing individuals' achievements, their qualities, reputation and skills.

Badges are often devised in order to make the participation in social media more engaging and motivating (Antin and Churchill, 2011). Obtaining a badge is something that should motivate users and it is also a mark of achievements within a community. In social media, badges can, indeed, serve as a synthetic representation of various aspects (although a badge does not need to represent them all) including community membership, authority, competence, experience, identity and reputation (Halavais, 2011). Badges may also support the transferability of skills, reputation and/or achievements to other platforms.

Badges are often conceptualised as a "game mechanic" and in literature they are often treated as an instance of gamification ${ }^{1}$ (Zichermann and Cunningham, 2011; Schell, 2010). Gamification is the use of game mechanics and other game elements in non game situations. Game mechanics are rules that shape the game experience. Gamification is a new concept, which is gaining momentum in User Experience research. The concept is also entering $\mathrm{HCl}$ conferences (Deterding et al., 2011) and there are also services such as Badgeville (http://www.badgeville.com) that offer gamification services with, as the name suggest, a strong focus on badges.

The concept of gamification originates in the areas of marketing and (positive) psychology (McGonigal, 2011) with a focus on making customers more loyal, and influencing their behavior toward desired results (such as buying a product) by the means of positive reinforcement (feedbacks and triggers). Under this marketing oriented umbrella a badge can therefore be seen as feedback meant to foster addictive behavior such as loyalty programs, something that suffers from some ethical concerns (Man, 2011). This, mostly correct, criticism of gamification as a way to create marketing feedback and triggers does not entirely undermine the role that badges could have in CMPs and social media more generally. If current existing contributions to badge design come only from gamification, this is perhaps because of a lack of $\mathrm{HCl}$ literature in general and not of gamification in itself.

Badges, for example, can help in fostering an Online Connected Learning (OCL) ecosystem.

\footnotetext{
${ }^{1}$ Badges have existed in military environments, for instance, long before gamification.
}

Where OCL is the type of learning that happens in online spaces, and which, is informal, open-ended and motivating for people. Badges can help formalise and recognise $\mathrm{OCL}$ achievements and skills enabling users to transfer these to other contexts.

A recent Digital Media and Learning Competition (http://dmlcompetition.net/Competition/4/about.php) supported by the MacArthur Foundation has been entirely devoted to the role of badges for fostering OCL. The competition has had tracks related to pure research on badges as well as on the design of badge systems. The design competition asked for the production of badges that could augment the infrastructure of the Mozilla Open Badge project (http://openbadges.org/). The Mozilla Open Badge is meant to foster the formalization of skills and achievements by the means of badges:

making it easy for anyone to issue, earn and display badges across the web -- through a shared infrastructure that's free and open to all.

Despite the clear focus of the competition on designing badge systems, contributors are proposing already-designed solutions and do not provide detailed description of the design process behind a badge system design.

\section{TIMU AND ITS REPUTATION SYSTEM}

In this paper we describe the process that led to the initial design of a badge system for the CMP timu. More specifically we account for the process that led to the description of the labels (see section 3.1) of a badge system meant to be a visual and efficient summary of the reputation of participants within the context of this platform. Reputation is a key concept of contemporary web platforms and can be defined as (Dellarocas, 2011, p. 4):

\footnotetext{
a summary of one's relevant past actions within the context of a specific community, presented in a manner that can help other community members make decisions with respect to whether and how to relate to that individual (and/or to the individual's works).
}

Reputation is also a form of trust: an attitude which allows for risk-taking decisions. In the digital environment people often interact with other unknown users and interaction is often risky. Reputation can support the creation of social order in digitally mediated interactions (Taddeo, 2010):

it is the kind of trust that one develops in an unknown agent by considering only the recommendations about that agent provided by other agents or by other information sources, such as newspapers or televisions. Referential trust is one of the main kinds of trust developed 
in digital environments in which communication processes are easily performed.

In web platforms a detailed and well-designed reputation system facilitates therefore trustworthy relationships among unknown participants. Reputation systems allow for better decisionmaking for users and bring structure to web communities (Farmer and Glass, 2010). With a reputation system in place the user is not "unknown" in the eyes of other users.

timu is a CMP whose goal is to stimulate the creation of a bottom-up and participative information ecosystem. Each timu user has a personal timu profile (Figure 1), which is composed of a personal picture, the name (e.g. Cinzia Massa) and username (e.g. cinzia), the number of inquiries (e.g. 2) to which she is contributing as well as the personal contributions (red icons) the user has made to the platform inquiries.

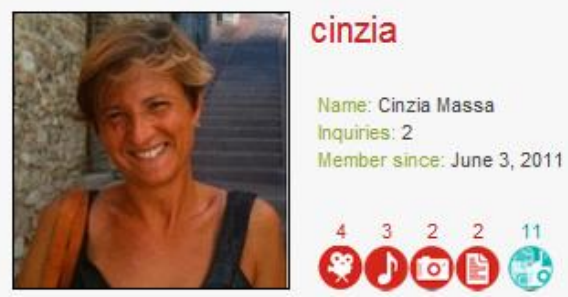

Figure 1: example of a timu user profile

timu has a reputation system (currently being developed) whose goals are to encourage individual participation and to stimulate the creation of a trusted network of participants. Reputation can be acquired with individual contributions or, in other words, with the upload of individual works in timu such as videos (first red icon of the profile), audio files (second icon), photographs (third icon), and written documents (fourth icon). For example, a person familiar with photography can enjoy a certain reputation that comes from the uploads she has made in timu and from the quality these uploads bring to timu inquiries. timu, indeed, hopes that citizens will be able to participate with their capabilities and abilities to create information that originates from civic life.

Besides tracking the individual's contributions /uploads, the reputation system's goal is to allow the identification of those users to whom more trust could be delegated. More trust means that the users will be able to increasingly undertake certain administrative tasks such as flagging inappropriate contents or leading new inquiries. The timu reputation system is organised around 13 numerical levels ${ }^{2}$ (from the entry level 0 to the final

\footnotetext{
${ }^{2}$ The progress between one reputation level and the next is not linear (i.e. the "distance" between all levels being the same) but it follows a exponential distribution.
}

level 12) and at each level the user acquires more administrative rights and/or unlocks new parts of the platform (see Table 1).

Table 1: Excerpt of the timu reputation table with achievements for the first four levels

\begin{tabular}{|c|c|}
\hline Reputation level & New right/platform feature \\
\hline 1 & EXTENDED USER PROFILE \\
\hline 2 & ABILITY TO FLAG \\
\hline$\cdots$ & $\ldots \cdots$ \\
\hline 12 & EDIT THE PLATFORM CONTENTS \\
\hline
\end{tabular}

\subsection{Named Levels rather than Numbered Levels}

We have identified a few key shortcomings with numbered levels ${ }^{3}$ (from 0 to 12 ) as a representation of reputation levels: they are too "context dependent" and they do not provide good information about the user reputation. Being too context dependent means that numbers do not provide enough information to assess the user reputation outside timu. For instance, saying that a user has reputation 3 is unclear outside timu. It could be 3 out of 5 levels (quite good reputation) or 3 out of 100 levels (very low reputation). Secondly, numbers do not give enough details about the participant's contribution to timu (is a person with level 3 a good contributor or not?). These shortcomings of the numbers as a representation of reputation led the design to team to recognise the need for a different representation. Badges were identified as a possible solution to both the contextual and the informational problem of current/numerical reputation representation.

In the Yahoo! pattern library there are two different patterns related to badges: non sequential and sequential. This second pattern, called "named levels" was considered an appropriate solution for our problem:

Define a family of reputation levels on a
progressive continuum. Each level is higher than
the one before it.
Unique names give the levels a fun and
approachable quality. Quick comparisons
between levels, however, become slightly more
difficult.

The Yahoo! pattern did provide a clue for the solution but not the solution in itself. The problem was therefore to identify a "family" of reputation names or labels able to represent numbered levels (from 0 to 12) of the timu reputation system. This was the central focus of the design experience.

\footnotetext{
${ }^{3}$ Numbers for representing reputation can be seen as the design pattern called "numbered levels", see http://developer.yahoo.com/ypatterns/social/people/reputation/n umberedlevels.html
} 
More specifically, the idea was not to have a label for each number but to have a label grouping three numbered levels at once (e.g. badge 1: levels 1-3; badge 2: levels 4-6 and so forth), so as to have a compact badge set of four badges covering the whole 12 timu reputation levels.

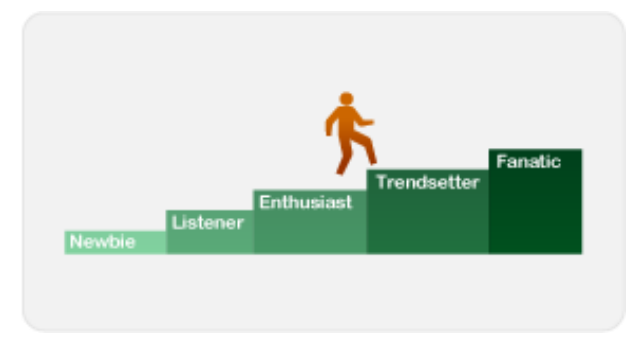

Figure 2: named levels from Yahoo! pattern library ${ }^{4}$

\section{DESIGN METHODOLOGY}

As design methodology for the identification of labels we have adopted a light version of the interaction design process described in Cooper et al (2007, p. 24). Because we were not designing a full web based product (e.g. an entire platform) or complex wireframes, but just the badge system, we decided for a reduced version of the process with emphasis only on selected aspects that are described in the next paragraphs.

\subsection{User Research}

In order to better understand the usage of badges in web communities we conducted a qualitative indepth case study. Our goal was to obtain a better idea of the role of badges in social media with particular attention to users' desiderata and also to identify key aspects of badge systems that we could use on our own design. In particular, we conducted a virtual ethnography (Hine, 2000) of the Mozilla Open Badge project. Ethnography is a qualitative method whose goal is to obtain greater awareness of the point of view of social actors. Virtual ethnography is instead the ethnography of online communities. The Open Badge project was selected after a preliminary identification of a number of suitable cases (including for instance foursquare and World of Warcraft), because of the Digital Media Competition and the debates about badges fostered by such an initiative.

The ethnography was conducted as part of the MA dissertation of one of the authors of this essay during the period from July 2011 to September 2011. Data was gathered from blogs of Mozilla Open Badge Developers, mailing lists, online articles and forum discussions. Data gathered was

\footnotetext{
${ }^{4}$ See

http://developer.yahoo.com/ypatterns/social/people/reputation/n amedlevels.html
}

analyzed using a grounded theory approach (Charmaz, 2006) in order to identify recurring themes. The user research lead to the following results, which partly confirms some of the few existing analyses of badge systems (Antinn and Churchill, 2010; Halavais, 2011):

- Badges have a key role in triggering motivation for user participation in web platforms;

- Badges can support the transferability of users' reputation, skills and achievements across contexts and different platforms;

- Badges can play a crucial community building role strengthening the ties among participants;

- Badges can play a crucial role in representing users' reputation, skills and achievements in online platforms.

These results helped us develop the requirements for the timu badge system as well as modeling a number of scenarios (Carroll, 1995) that we used during design activities.

\subsection{Personas \& Scenarios}

With the results from the ethnography at hand we developed a number of personas and context scenarios (how the badge would fit into the participants' lives). The design team already had personas that were prepared for the design of the timu user profile. These were just adapted to suit the specific design task of badges. For the design of the named levels (i.e. labels), the team decided to use 4 personas each corresponding roughly to a set of numbered levels (level 0-3: person Gianluca; 4-6: person Giovanna; 7-9: person Olga; 10-12: person Francesca). This is one of our personas

\begin{abstract}
Gianluca is 28 years old ${ }^{5}$. He recently graduated in philosophy at the University of Parma and is now working as a clerk at a post office in a town in the Emilia Romagna Region. Recently Gianluca moved into a small rented apartment and, during leisure time, uses his computer to keep in touch with friends through Facebook and Twitter. He also loves playing online games. Using social networks, he got back in touch with old friends that he had when, as a child, he lived in another Italian city. Gianluca wouldn't mind knowing nice people on Facebook living nearby that he could meet offline during his free time.
\end{abstract}

Context scenarios were developed using the results of the ethnography as well as using knowledge of the current timu user base. Four scenarios were developed taking in account the set of numbered levels (e.g. Scenario 0-3, Scenario 4-

\footnotetext{
${ }^{5}$ Personas had each their own photos and further visual details, which are not reported here.
} 
6 and so forth). We propose here an example where we also emphasize in bold some of the aspects that came from the ethnography results:

\section{Scenario for the levels 0-3, Person Gianluca}

Gianluca spends a lot of time on his PC when he is not at work. On Facebook he has seen that a friend has shared some new content via a platform called timu. Gianluca got interested and wanted to know more about this "timu" and typed the url www.timu.it on his browser.

Everything on timu looked very interesting. He decided to join timu to participate in an inquiry on "The twenty years of the web". After posting his first contribution he received a notification informing him that he has just unblocked his first badge. Happy about this new discovery [motivation] he feels immediately involved in this new community [community] and, especially, feels motivated to post new comments or upload other material. Gianluca was already familiar with badges [portability]. He knows badges, which represent achievements and skills [reputation], from his personal experiences in playing World of Warcraft. He also thinks it would be quite engaging to gain further badges [motivation] in the future.

As we will better see, personas and scenarios have been used during the design activities.

\subsection{Requirements Definition}

With the ethnography results as well as with the preliminary identification of the general objectives of a badge system a number of requirements were identified by the team. The requirements for the timu badge system can be summarised as follows:

(i) Badges should take the form of the pattern Named Levels: badges should be labels with a progressive increase, so as to differently represent numbered levels. This will allow the timu reputation to be better represented to users.

(ii) The labels must also be easily understandable outside timu. This will facilitate portability of reputation, for example on the participant's personal blog.

(iii) The labels of badges need to provide participants' specific motivations both in how they contribute to timu as well as for the obtaining of a badge.

(iv) The named levels should, where possible, create a sense of participation in the community of timu both inside and outside the platform.

\section{DESIGN FRAMEWORK}

In this section we describe the design process that led to our named levels. Our work could be divided in three steps: preparation, design and post design. During the final step we created our badge's design vision for the timu platform.

\subsection{Pre-Session preparation}

A pre-design session was planned for the design team with a focus on making a detailed schedule for the design sessions. During the preparatory stage it was decided to have two different design sessions with users and to conduct the same experiment/exercise with each group of users. The advantage of doing two sessions is to create different views within the two different groups as different users can emphasize different aspects. In some cases, as has happened in this experience of design, people treat similar elements in different moments and with different terms, also providing different visions of possible solutions to a problem.

During the preparatory stage the following schedule for the design sessions was decided: to prepare an introductory presentation towards the goal of the session and towards the goals of the timu reputation system; to present users with the personas and scenarios; to present users with the design exercise (that was prepared by the team see next section); to give the participants the following materials: the list of requirements, a copy of each persona with the corresponding scenario and the exercise templates; to conduct the exercise with them; and finally to foster a final discussion.

\subsection{Design Exercise}

For the design of labels we have conceived an exercise which is an adaptation of a popular User Experience exercise (from Adaptive Path) called "six-to-one" (for a description see Bowles and Box, 2011). In the original exercise, participants receive a template with six basic grids and are asked to produce six interface sketches within a specified time frame ${ }^{6}$. After this, participants are asked to select their best idea out of the six and to report it on a single (one) grid template. The timu design team considered that this exercise could be used for the design of badge levels and devised an adaptation called "three-to-one" with also a specific template for named levels (Figure 3).

A template with three simply named level grids (each with 4 green boxes) was prepared (Figure 3). Each grid represented roughly the Yahoo! named

\footnotetext{
${ }^{6}$ Material for conducting the original exercise are available here http://www.boxuk.com/upload/sketching/downloads/SketchingTe mplates.pdf

${ }^{7}$ In our exercise the production of badges was done individually, but potentially it could also be done by a group of users.
} 
levels pattern which we thought we would introduce during the design session. The same pattern image was reported on the right upper side of the template in order to facilitate its use. Further components of the template are: a recall to numbered levels of the reputation system corresponding to each of the named levels (e.g. 0-3 under the first box; 4-6 under the second box and so forth). Also corresponding personas/scenarios were placed below each box. We thought that these two additions would help participants in developing their ideas.

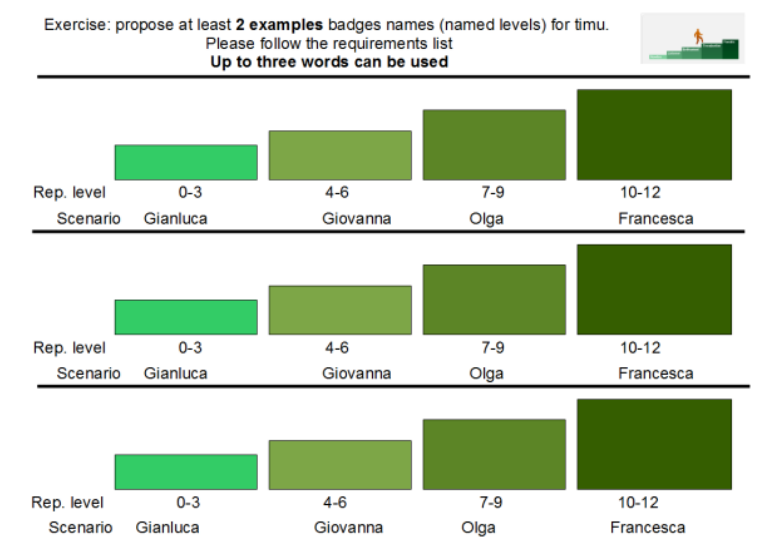

Figure 3: "three-to-one" template for named levels

A second template with just one single named level grid was then prepared. As in the "six-to-one" exercise, the idea was to ask participants to select their best solution. The best solution would then be discussed by participants and the design team in order to better understand the logic of each proposed idea and to gather further material for the design of reputation labels.

\subsection{Design Session}

The purpose of the design sessions was to have potential users and actual users of the timu platform identify and propose ideas for the named levels of the badge system. Both sessions took place on the same day, 21 December 2011, at the meeting room of the <ahref Foundation and lasted for about 3 hours. The first session took place in the morning, starting at 9:30. The second session took place in the afternoon starting at 14:30. The two sessions were attended by ten people. These people/users were selected and contacted based on previous knowledge and experiences with the platform. We had planned to have 5 people for each session. However, the morning session was attended by three people only. The missing people from the morning session participated in the afternoon session, because they had transportation problems and this prevented them from taking part in the morning session. The afternoon session therefore had seven participants. This issue did not negatively affect the sessions.
Design sessions were conducted by one of the authors and were organised according to what was planned in the preparation phase of the design. Firstly the author described to participants the goal of the design session, namely the need for designing something related to the reputation system of timu. Then, the mechanics of the timu reputation system were introduced as well as the need to represent numbered levels (i.e. reputation levels from $0-12$ ) in different ways. Reasons for this need (i.e. lack of contextual information provided by numbers) were also described. Badges were then introduced as a concept both in general terms and specific terms (i.e. badges in web based online environments). To better explain what badges are, named level examples were proposed related to military hierarchy and to web platforms with examples from World of Warcraft and Yahoo! sport. Another topic of the presentation was to provide information about the named level pattern and its possible relation to the timu reputation. The named levels picture (figure 2) was presented and was related to the numbered levels of the timu reputation (figure 4).

Also the requirements of the badge system were presented. Participants were told that the purpose of the session was to identify and propose names/labels for the timu badge system that would be able to replace the numbers and to express the idea of progress with effective names. During the presentation the personas and scenarios prepared for the design session were also presented. It was explained to participants that these would help them in proposing the labels.

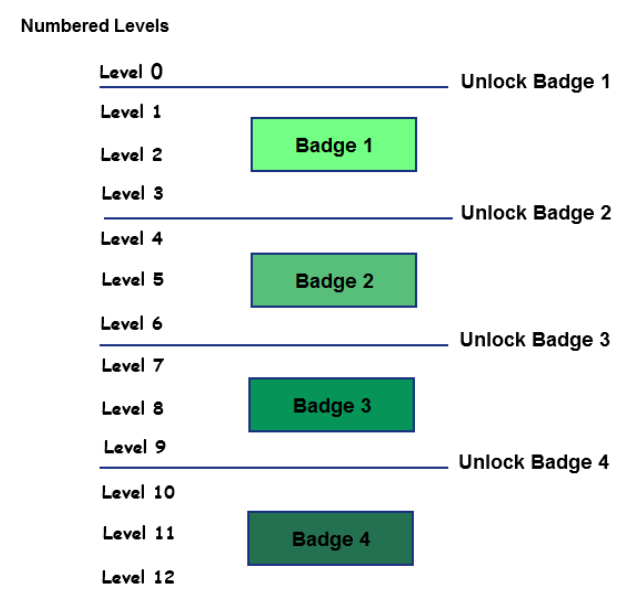

Figure 4: named levels and timu numbered levels

The "three-to-one" exercise was then introduced, explaining to users that they were required to propose 3 different label solutions. The following material was then given to participants: a list of the requirements; a copy of each persona and scenario; and a template with the "three-to-one" 
exercise. Approximately 20 minutes were given for completing the task.

After completing the task, users were provided with another template with the space for proposing just one solution. They were asked to choose the best of their three options. The final templates were then collected and discussed by participants using a sketch board.

\subsection{The discussion and requirements}

After each exercise the design team fostered a discussion among participants. The focus of discussions was to consider how much each of the proposed best solutions would meet the requirements. Each participant was asked to explain to others his/her proposed solution. Some important results were achieved during the discussions. The reflections we provide here come from our analysis of the exercise materials, including analysis of the design session audio file transcripts. We also provide a table (below) showing all the proposed best solutions.

Table 2: Best named levels solutions proposed by users

\begin{tabular}{|l|l|l|l|l|}
\hline \hline $\begin{array}{l}\text { Us } \\
\text { er }\end{array}$ & $\begin{array}{l}\text { Levels } \\
\mathbf{0 - 3}\end{array}$ & $\begin{array}{l}\text { Levels } \\
\mathbf{4 - 6}\end{array}$ & $\begin{array}{l}\text { Levels } \\
\mathbf{7 - 9}\end{array}$ & $\begin{array}{l}\text { Levels } \\
\mathbf{1 0 - 1 2}\end{array}$ \\
\hline 1 & $\begin{array}{l}\text { Junior Civic } \\
\text { Reporter }\end{array}$ & Civic Reporter & $\begin{array}{l}\text { Master Civic } \\
\text { Reporter }\end{array}$ & $\begin{array}{l}\text { Senior Civic } \\
\text { Reporter }\end{array}$ \\
\hline 2 & Interested & Active & Proficient & $\begin{array}{l}\text { Knowledgea } \\
\text { ble }\end{array}$ \\
\hline 3 & $\begin{array}{l}\text { Junior } \\
\text { Member }\end{array}$ & $\begin{array}{l}\text { Fellow } \\
\text { Member }\end{array}$ & $\begin{array}{l}\text { Senior } \\
\text { Member }\end{array}$ & Moderator \\
\hline 4 & Beginner & Intermediate & Advanced & Proficient \\
\hline 5 & Occasional & Participative & Constant & Professional \\
\hline 6 & $\begin{array}{l}\text { Citizen } \\
\text { Journalist } \\
(1 / 2 / 3 \\
\text { Bronze } \\
\text { stars) }\end{array}$ & $\begin{array}{l}\text { Citizen } \\
\text { Journalist } \\
\text { stars) }\end{array}$ & $\begin{array}{l}\text { Citizen } \\
\text { Journalist } \\
(1 / 2 / 3 \text { Gold } \\
\text { stars })\end{array}$ & ..... \\
\hline 7 & First steps & $\begin{array}{l}\text { Active } \\
\text { participant }\end{array}$ & $\begin{array}{l}\text { Extraordinary } \\
\text { engagement }\end{array}$ & $\begin{array}{l}\text { Model } \\
\text { contributor }\end{array}$ \\
\hline 8 & $\begin{array}{l}\text { Motivated } \\
\text { Citizen }\end{array}$ & $\begin{array}{l}\text { Citizen with } \\
\text { consciousness }\end{array}$ & $\begin{array}{l}\text { Citizen with } \\
\text { awareness }\end{array}$ & $\begin{array}{l}\text { Participating } \\
\text { citizen }\end{array}$ \\
\hline 9 & Tourist & Excursionist & Explorer & Sherpa \\
\hline 10 & Puzzle & Tree & Column & ..... \\
\hline
\end{tabular}

\subsubsection{Progressive names}

Users of the morning session highlighted that a label can be easily expressed by a noun such as "participant" or "reporter". But to define reputation levels in a progressive way this is clearly not enough. Participants of both sessions said that a further name or adjective would be crucial (although not necessarily) for creating a sense of progression. An example of progressive names is the case 6 , with the noun "citizen journalist" accompanied by progressive names similar to those of Olympic medals (i.e. bronze, silver and so on), which also give a sense of upward progression of named levels.

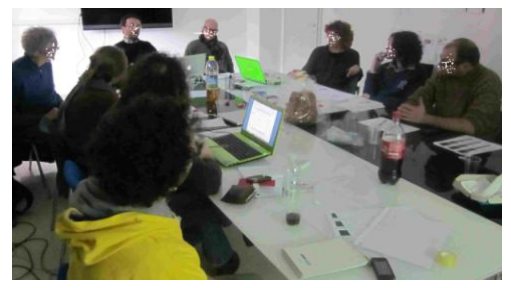

Figure 5: moment of the discussion

An adjective instead is a word that determines the quality of nouns or their situation. Participants therefore underlined that for meeting the progression of named levels a progressive adjective would better accompany the noun. As pointed out by a participant in the morning session:

\section{the adjective describes an argument, a growth. The noun must instead contextualise and tell what you're getting ${ }^{8}$.}

User number 3's proposal is an example of this with a noun "member" accompanied by a series of upward adjectives (Junior, Fellow, Senior). Another participant pointed out that the noun (e.g. member) gives information about the context of the platform while adjectives instead relate to the user's increases of reputational levels. Number 1 is an example of this with the nouns "civic reporter" accompanied by progressive adjectives (Junior, master and so on).

The proper selection of progressive adjectives and/or names allows us to meet the first requirement: creating progressive labels. During the discussion it emerged that some choices were definitely better in characterizing progression and in particular:

i. those similar to the language proficiency system (beginner, intermediate and so forth) (cases 2 and 4);

ii. those recalling Olympic medals (case 6);

iii. those recalling seniority (cases 1 and 3);

Other proposed solutions did not provide a clear progression. For instance in the solutions 5 or 8 the progressive logic is not clear. While discussing solution 5 , a participant noticed that:

You can see the progression if you look at all four together. The central pair [participative, constant] progression however is not immediately apparent.

\footnotetext{
${ }^{8}$ Excerpts were translated from Italian by us. Originals of the excerpts are available here: $\underline{h t t p: / / g o o . g l / / T 21 D ~}$
} 
Those choices that did not provide a clear sense of progression were therefore identified by users themselves.

\subsubsection{Portability}

Portability is the second key requirement of the timu named levels. Most participants in their best models emphasized the importance of universally understandable labels. Portability means that a label should provide immediate feedback about the reputation level, when a badge is seen outside the context of timu. For example some participants emphasized the importance of universallyunderstandable nouns related with the timu platform, in this way linking the context (timu) with the outside world. Therefore nouns such as "reporter or "citizen journalist" (cases 1 and 6) could be understandable outside timu. All these nouns are also strongly linked to the platform goals. However, for understanding the reputation levels, contextual nouns are not enough. The noun "reporter" as such does not emphasize progression or reputational levels. Further adjectives and names characterizing progression are therefore important.

During the discussion, four out of ten people said that the adjectives related to the language proficiency system are quite universally understandable: beginner, intermediate, advanced. One of the people which proposed these adjectives emphasized their portability:

\footnotetext{
This system has maximum portability because it is universally used not only at platform level but at any language proficiency rating level.
}

These four adjectives that qualify the person's activities, effectively express the idea of progression. Seeing the label "beginner reporters" for instance provides immediate information about the reputation level (i.e. a user with a low level, just at the beginning of her experience). The label "expert reporter" also provides immediate feedback about the reputation (i.e. the user is quite expert).

A second case was identified as fully portable: those with the names related to Olympic medals. Also this model is universally understandable because of the wide diffusion of this system to characterise winners in sporting competitions.

\subsubsection{Motivation}

Another key requirement is the motivation that badges should trigger. This requirement emerged from our user research on the case study of Mozilla Open Badge. All participants said that they tried to express labels able to motivate people's participation in timu. User number 7's example has a clear focus on user motivation and comes from the personal experience of a user with video game platforms which often provide badges with funny and entertaining labels.

Another solution, however, emerged as clearly motivational and able to better represent numerical levels (in this way augmenting also the progressive names). This is the case for number 6 . The person proposing this system said this came from his experience as an alpine skiing instructor at a professional level:

For four years I was an alpine ski instructor and we use stars: 1, 2, 3 bronze-stars, 1, 2, 3 silverstars and 1, 2, 3 gold-stars which are an evaluation of how good the person is at skiing.

The discussion about this solution lead to a realization that each of the four badges could be further augmented by stars or points. Therefore the "badge1" would also have 1, 2, 3 stars corresponding to level 1 , level 2 and level 3 . The "badge 2" would also have 1, 2, 3 stars corresponding to levels 4,5 and 6 and so forth. This idea would allow a better granularity of reputation representation and provide more motivation because a user would unlock not only badges at each of the 3 levels but also unlock a "star" at each level. A participant noticed that this system:

is very motivating if at the beginning everything is turned off. I really like the idea of putting the stars in the badge. If you are between 0 and 1 you will get a star.

We considered this suggestion an important contribution in meeting the motivational requirement of our badge system.

\subsubsection{Participation}

Another requirement for badges is their role in triggering participation with the community. Some of the proposed solutions (5 and 7 ) have an emphasis on participation. The person proposing solution 5 also emphasized how personas and scenarios helped this definition:

I saw Gianluca as someone who contributes occasionally. [...] Giovanna instead is "participative" in the sense that she is already present on the platform, she has already contributed.

It should be noted however that not only words directly related to "participation" (e.g. participative) was understood as meeting the requirements. In fact, another user pointed out that his choice of other words was made with participation in mind:

"member", because we were thinking about participation.

The noun "member" therefore was meant to give a sense of membership. "Member" however does not 
give a sense of activity and contribution to the creation of information but it only gives a sense of participation. The design team realised that this requirement was poorly met by the user proposals.

\subsection{Post-Design: design vision}

On January $10^{\text {th }} 2012$, approximately 3 weeks after the exercise, the design team met in order to discuss the results. The time between the sessions and the final meeting was used to transcribe and analyze audio files. The goal of the meeting was to formalise a design vision for named levels for the timu reputation. The vision can be described using the original requirements:

(i) Progressive Named Levels: the Olympic medals rhetoric (bronze / silver / gold) and the language proficiency rhetoric (beginner / intermediate / advanced) were both considered the best solutions. Some changes were, however, introduced as in tables 3 and 4 . For instance the Olympic medal model has only 3 steps so it was decided to add platinum after gold. In the case of the language proficiency we decided to use "expert" instead of "advanced" and to add "master" as the fourth level. This change was considered to provide a better sense of progression over 4 levels.

(ii) Portability: Nouns should reflect the user's ability to contribute to timu as well as the contextual-universal relation between timu and the remainder of the information ecosystem: the noun "reporter" was considered the best option among those selected by the users. The design team also decided to resort to a noun often used by users in their "three-to-.one" models but which was not picked up in their "best models": the word "contributor". Contributor gives a sense of active participation.

In relation to progressive named levels, the chosen systems - language proficiency and Olympic medals alike - were both considered easily portable and understandable also outside timu. This also emerged from the user discussions.

(iii) Motivation: the idea of having stars for each numbered level was considered an important motivational aspect. The design team decided to adopt this view.

(iv) Participation: the design team decided that the name of the platform would always accompany the named levels to give a sense of participation (e.g. "timu" expert reporter; "timu" silver contributor). This was decided because user proposed models did not sufficiently meet the original requirement.
Based on these considerations 4 different systems of named levels were created.

Table 3: Contributor Named Levels

\begin{tabular}{|l|c|l|l|}
\hline \hline $\begin{array}{l}\text { Badges } \\
\text { Contributor }\end{array}$ & Levels & $\begin{array}{l}\text { Solution 1 } \\
\text { Language } \\
\text { proficiency alike }\end{array}$ & $\begin{array}{l}\text { Solution 2 } \\
\text { Olympic } \\
\text { medal alike }\end{array}$ \\
\hline Badge 1 & $1-3$ & $\begin{array}{l}\text { timu beginner } \\
\text { contributor }\end{array}$ & $\begin{array}{l}\text { timu bronze } \\
\text { contributor }\end{array}$ \\
\hline Badge 2 & $4-6$ & $\begin{array}{l}\text { timu intermediate } \\
\text { contributor }\end{array}$ & $\begin{array}{l}\text { timu silver } \\
\text { contributor }\end{array}$ \\
\hline Badge 3 & $7-9$ & $\begin{array}{l}\text { timu expert } \\
\text { contributor }\end{array}$ & $\begin{array}{l}\text { timu gold } \\
\text { contributor }\end{array}$ \\
\hline Badge 4 & $10-12$ & $\begin{array}{l}\text { timu master } \\
\text { contributor }\end{array}$ & $\begin{array}{l}\text { timu platinum } \\
\text { contributor }\end{array}$ \\
\hline
\end{tabular}

Table 4: Reporter Named Levels

\begin{tabular}{|l|c|l|l|}
\hline $\begin{array}{l}\text { Badges } \\
\text { Reported }\end{array}$ & Levels & $\begin{array}{l}\text { Solution 3 } \\
\text { Language } \\
\text { proficiency alike }\end{array}$ & $\begin{array}{l}\text { Solution 4 } \\
\text { Olympic } \\
\text { medal alike }\end{array}$ \\
\hline Badge 1 & $1-3$ & $\begin{array}{l}\text { timu beginner } \\
\text { reporter }\end{array}$ & $\begin{array}{l}\text { timu bronze } \\
\text { reporter }\end{array}$ \\
\hline Badge 2 & $4-6$ & $\begin{array}{l}\text { timu intermediate } \\
\text { reporter }\end{array}$ & $\begin{array}{l}\text { timu silver } \\
\text { reporter }\end{array}$ \\
\hline Badge 3 & $7-9$ & timu expert reporter & $\begin{array}{l}\text { timu gold } \\
\text { reporter }\end{array}$ \\
\hline Badge 4 & $10-12$ & timu master reporter & $\begin{array}{l}\text { timu platinum } \\
\text { reporter }\end{array}$ \\
\hline
\end{tabular}

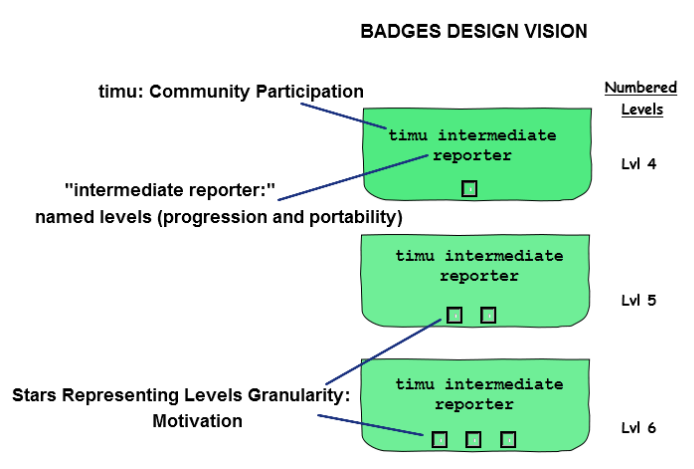

Figure 6: Badges Design Vision

Sketches representing each of these models were also prepared. These sketches would provide a general graphical idea of the concepts developed during the design. Figure 6 provides an example also showing an emphasis on how the design choices meet the original requirements.

\section{VALIDATION}

On January $20^{\text {th }} 2012$ badges were validated during a session in which one of the designers presented the result of this research to a number of people involved in the creation of the timu platform: 
the president and the director of the ahref Foundation, the team manager and another researcher. The whole design process was reconstructed for them including the identified requirements and how the four proposed solutions would meet them.

The solutions with the Olympic medal rhetoric were discarded during the validation as they imply competition. timu is not a competitive community and therefore the medal progression would not adequately represent the spirit of the community.

The solutions related to language proficiency were instead considered suitable for the platform because they imply a learning activity and personal improvement, something directly related to the goals of timu. Also the noun "reporter" was considered better than "contributor" because it is closer to the idea of producing a bottom-up civic information ecosystem. Solution number 3 was validated for further graphical development.

\section{CONCLUSION: LESSONS LEARNED}

Badges are gaining momentum on the social web but known design experiences are very few. In this paper we presented a design experience related to badges and named levels for Civic Media. In particular we showed how we solved the problem of representing numerical levels of reputation for the users using named levels. Our design experience provided interesting reflections about the use of nouns and adjectives for building the badge's named levels. A further contribution of our design experience is the "three-to-one" exercise. Although in itself the exercise could be still improved, it provides an interesting and reusable solution for the design of a badge's named levels.

Finally, it emerged during design sessions, that users brought their past experience (for example as online gamers) into their formulation of named levels and in discussions. The case of the alpine skiing instructor is revealing in this regard. His idea of stars was incorporated into the badge's design vision and offered an interesting solution for representing the granularity of reputation levels.

\section{REFERENCES}

Antin, J. and Churchill, E. F. (2011) Badges in Social Media: A Social Psychological Perspective. Gamification Workshop, ACM Conference on Human Factors in Computing Systems (CHI2011), Vancouver, BC, Canada, 7-12 May, http://research.yahoo.com/pub/3469 (15 November 2011).

Atkinson, B. (2006) Captology: A critical review. In Proceedings of the First International Conference on Persuasive Technology for Human Well-Being,
Eindhoven, The Netherlands, 18-19 May, pp. 171182. Lecture Notes in Computer Science, Vol. 3962, Springer, Berlin.

Bowles, C. and Box, J. (2011) Undercover User Experience Design. New Riders, Berkeley, CA.

Carroll, J. M. (1995) Scenario-based design: Envisioning work and technology in system development. John Wiley \& Sons, New York.

Charmaz, K. (2006) Constructing Grounded Theory. Sage, Thousand Oaks.

Cooper A., Reinman, R. and Cronin, D. (2007) About Face 3.0: The Essentials of Interaction Design. John Wiley \& Sons, Indianapolis, IN.

DeBiase, L. (2011) Cambiare Pagina. BUR, Milano. Dellarocas, C. (2011) Designing Reputation Systems for the Social Web. In Masum, H. and Tovey, M. (eds), The Reputation Society, MIT Press, Cambridge, MA.

Deterding S., Sicart, M., Nacke, L., O'Hara, K. and Dixon, D. (2011) Gamification: Using Game Design Elements in Non-Gaming Contexts. Workshop Call for Papers, ACM Conference on Human Factors in Computing Systems (CHI2011), Vancouver, BC, Canada, 7-12 May, http://gamificationresearch.org/wp-content/uploads/2011/04/01Deterding-Sicart-Nacke-OHara-Dixon.pdf November 2011).

Farmer, F. R. and Glass, B. (2010) Building Web Reputation Systems. O'Reilly Media: Sebastopol.

Fogg, B. J. (2002) Persuasive Technology: Using Computers to Change What We Think and Do. Morgan Kaufmann, San Francisco.

Gillmor, D. (2004) We the media. O'Reilly, Sebastopol.

Halavais, A. (2011) A Genealogy of Badges. Information, Communication and Society, DOI:

10.1080/1369118X.2011.641992

Hine, C. (2000) Virtual Ethnography. Sage, London.

Jenkins, H. (2007) What is Civic Media. Non Verbatim Transcript of a Talk given at MIT, 20 Sept. 2007. http://web.mit.edu/commforum/forums/civic media.html (20 January 2012). Man, P. (2011) Playing the Real Life. The Ludification of Social Ties in Social Media. http://www.philipman.net/wp-

content/uploads/2011/03/NMT FinalDraft Man1.pd f (16 June 2011).

McGonigal, J. (2011) Reality is Broken. Jonathan Cape, London.

Schell, J. (2010) Design outside the Box, Key Note Speech at DICE 2010, http://www.g4tv.com/videos/44277/DICE-2010-

Design-Outside-the-Box-Presentation/

November 2011).

Taddeo, M. (2010) Modelling Trust in Artificial Agents. Minds and Machines, 20(2), 243-257.

Zichermann, G. and Cunningham, C. (2010) Gamification by Design. O'Reilly Media, Sebastopol. 